\title{
Reconstructive Surgery for Aortic Valve Disease
}

\author{
Paulo José F. Ribeiro, Paulo Roberto B. Évora, Walter V. A. Vicente, Antonio Carlos Menardi
}

Ribeirão Preto, SP - Brazil

Aortic valve repair, one of the first procedures performed in the history of heart surgery, was somewhat ignored compared with valvar replacement by artificial prostheses, which became very popular in the sixties. Difficulties related to myocardial protection, in association with the relative paucity of intra- and postoperative technical resources then available well as the apparent simplicity of valve replacement procedures were responsible for this initial indifference towards aortic valve reconstructive surgery.

Cumulative worldwide experience, however, soon showed that the implant of valvar prostheses actually represented a palliative operation characterized by the substitution of one disease by another. This fact prompted several services to explore and improve valve repair techniques, notably for correction of aortic valve regurgitation. In this arena, the great contribution of the European school, led by Carpentier ${ }^{1}$ and Duran ${ }^{2}$ has been remarkable, while in America, Cosgrove, et al ${ }^{3}$, David ${ }^{4}$ and Shapira, et al ${ }^{5}$ have also developed new techniques and popularized and standardized other techniques already in existence.

Good results from conservative valve operations, particularly for mitral valve disease, soon established the superiority of valve repair surgery, in selected cases, leading many groups to also explore the mechanical and functional reconstruction of the aortic valve. Currently, several procedures, some revived and improved, others new, account for a relatively large group of techniques for aortic valve repair and represent a very challenging area. This text is intended to review the surgical techniques more commonly applied to conservative aortic valve repair surgery.

Historical considerations - In 1914, many years before the advent of the cardiopulmonary bypass, Tuffler, using a retrograde approach, dilated the aortic valve digitally, before mitral commissurotomy was attempted ${ }^{6}$. This accomplishment inspired the development of different techniques of aortic valvotomy in the fifties ${ }^{7-10}$, with varying degrees of both success and complication, including valvar insufficiency.

In 1958, Lillehei, et al ${ }^{11}$, began aortic valve surgery

CECORP-Centro Especializado do Coração e Pulmão de Ribeirão Preto, Hospital do Coração de Ribeirão Preto/Fundação Waldemar B. Pessoa, Faculdade de Medicina de Ribeirão Preto-USP e Faculdade de Medicina da UNAERP Mailing adress: Paulo J. F. Ribeiro - Rua Quintino Bocaiúva, 171 - 14015-160 Ribeirão Preto, SP using cardiopulmonary bypass and, in the sixties, Mulder, et al ${ }^{12}$ and Garamella, et al ${ }^{13}$ introduced the concept of commissural plication, later popularized by Cabrol, et al ${ }^{14}$ and Trusler, et al ${ }^{15}$. A series of attempts directed at remodeling or replacing the aortic leaflets then ensued, using plastic materials ${ }^{16-18}$, autologous pericardium ${ }^{17-19}$ and homologous tissues ${ }^{20}$. Of these, the work of Senning ${ }^{21-24}$ involving aortic valve leaflet restoration with fascia lata stands out. After 13 years of follow-up, this same author called attention to the calcific degeneration of this material, along with accumulation of fibrous tissue, both responsible for a high incidence of aortic insufficiency.

In Brazil, Puig ${ }^{25}$ introduced human dura mater preserved with glycerin for valve prostheses manufacturing, valvar remodeling, cardiovascular repairs, and other surgical applications. Clinical application of glutaraldehyde treated bovine pericardium came next and due to its great availability this material came to be extensively used for valve replacement and repair, particularly of the mitral valve ${ }^{26-29}$. Application of this biologic tissue for surgical repair of the aortic valve damaged either by rheumatic fever or by congenital or degenerative disease has been very exciting ${ }^{30-32}$.

\section{Anatomical and physiological considerations}

Familiarity with the anatomy and physiology of the normal aortic valve is extremely important for the success of surgical corrections of the diseased valve.

The normal aortic valve is made up of three cusps of similar size, the detection of malformed valves with a bigger or smaller number of cusps being uncommon. The cusp implantation bases of semilunar or semicircular shape determine the transition between the left ventricle infundibulum and the aorta. Each implantation base measures twice as much of the cusp free border and is made up of tissue rich in collagenous material. Like a suspension bridge, the three arches of implantation are interlinked at the level of the commissures $^{33}$. The aortic wall diametrically opposite to each cusp is protruded and thinned, in spite of resistance due to the presence of fibrous tissue. From the inside, the three wall dilations just described are called sinuses of Valsalva. The right and left coronary ostia generally originate separately from the sinuses of Valsalva, but have the same name, whereas the posterior sinus is called a noncoronary sinus.

The aortic valve cusps, also known as leaflets, shells or valves are thin and have a smooth surface, except close 
to the free border, where one may notice a narrow strip of tissue, known as lunula, which is made of grooves running parallel to the free border. The lunula represents the cusp coaptation zone during valvar closure. Interestingly, close to the commissures, the lunulae generally show perforations that seem to lack any pathological meaning once this finding is not associated with valvar incompetence. Halfway between the commissures, each lunula exhibits a small fibrous nodule called the nodulus of Arantius that converge during valvar closure at a point corresponding to the center of an imaginary circle whose diameter equals the total length of the free border of the 3 cusps. These details are very important for conservative surgical strategies.

At the level of the tips of the commissures one can identify an annular zone, rich in fibrous material and thicker than the adjacent aorta, called the sinotubular junction, junction ring, superior ring or sinotubular ring, also referred to as the more distal component of the aortic valve ${ }^{34}$. Internally, between the sinuses of Valsalva, three triangular fibromuscular areas are delimited by the cusp implantation bases having its tips directly attached to the sinotubular ring.

Aortic valve dimensions are not static because the sinotubular ring diameter changes with the heart cycle, increasing $16 \%$ during ventricular systole as compared with its diastolic caliber. In cases of ascending aorta ectasia, the fixed dilation of the sinotubular ring is the major determinant for valvar reflux, denoting the importance of its diameter reduction for correction of aortic incompetence.

The sinuses of Valsalva generate systolic blood flow vortexes, initially described by Leonardo da Vinci ${ }^{35}$. Besides avoiding the occlusion of the coronary ostia, the vortexes push the cusps medially so as to promote their coaptation as soon as ventricular ejection ceases, thus preventing protodiastolic regurgitation.

Different studies addressing the mechanism for aortic valve closure have pointed out that the cusps, besides being very delicate, show specific weight quite similar to blood. For this reason, they flip at the smallest changes in blood flow, which makes the abrupt pressure changes during the heart cycle the main force for opening or closing the aortic valve. It is known, on the other hand, that the contraction of the infundibular myocardium surrounding the valve by reducing the diameter of the latter allows for a smaller protrusion of the leaflets during valve opening as well as favors leaflet coaptation during valve closure. This fact depicts the ventricular outflow contraction as a safety mechanism for prevention of aortic valve insufficiency.

\section{Surgical techniques}

The surgical techniques for aortic valve restoration are designed to repair the following alterations: 1) dilation of the aortic ring; 2) prolapse of the sinuses (frequently the right coronary) into the left ventricle; 3 ) faulty mobility of the cusps due to thickening, or calcification, or both; 4) fibrotic retraction, perforation and laceration of the cusps caused by infectious, or inflammatory processes, or both 5) congenital defects and 6) traumatic lesions.
Results of aortic valvoplasty shall improve as the surgeon accumulates experience in analyzing pathological valve anatomy and, at the same time, selecting the most appropriate techniques for each case. Contrary to the mitral valve, where anatomy facilitates valvoplasty, reconstruction of the aortic valve, due to its smaller number of anatomical components to be dealt with during the operation, requires greater creativity and skill from the surgeon.

Aortic valve exposure is best provided by medium sternotomy followed by anterior oblique aortotomy directed to the annulus of the noncoronary sinus of Valsalva. This approach provides good visualization of all important valve structures and facilitates the operation. Cardioplegic myocardial preservation must be rigorous, whatever the adopted technique, blood or crystalloid, antegrade or retrograde, normothermic or hypothermic, intermittent or continuous. Aortotomy closure at the end of the procedure requires special attention. Single or double suture with 4.0 polipropilene is, in general, easy and safe although, sometimes, dacron felt strip suture reinforcement is recommended.

From a didactic point of view, reconstructive aortic valve surgery can be applied to three different lesion categories: (A) Stenosis; (B) Insufficiency and; (C) Combined lesions, aortic stenosis and insufficiency.

A) Aortic stenosis. For this lesion, valve commissurotomy plus debridement of fibrotic areas and decalcifications is the rule.

Calcium deposit debridement with a rongueur, as well as liberation of both fibrotic and commissural fusion, need to be accomplished, even risking cusp perforations, which can be patched with autologous or heterologous pericardium, sutured with running polipropilene stitches. Ultrasonic devices, similar to the ones used in dentistry, were tried for calcific debridement some years ago, but without long lasting results ${ }^{36-41}$.

In the presence of commissural fusion, classic commissurotomy is accomplished, complemented by free edge thinning of the contiguous portions of the sinuses ${ }^{2,39}$ (fig. 1), by means of a surgical blade or high-speed electric raspers.

Congenital aortic stenosis in young patients is a subgroup where conservative surgical options are limited, although two recent publications introduced an ingenious technical artifice for the preservation of bicuspid aortic valves. Tolan ${ }^{42}$ and Kadri ${ }^{43}$ working independently came up with the idea of transforming the bicuspid valve into a tricuspid one by excising the rudimentary commissure and replacing it with a new one made up of a biological membrane preserved in glutaraldehyde. A tissue patch shaped like an isosceles triangle is sutured to the leaflet edges resulting from the division of the rudimentary raphe and then attached to the aortic wall at the commissural levels (fig. 2)

B) Aortic insufficiency - Conservative surgical correction for aortic valve regurgitation can be obtained by means of a great variety of technical resources, including cusp resuspension, annuloplasty, commissuroplasty and partial cusp resection followed by cusp reconstruction with 


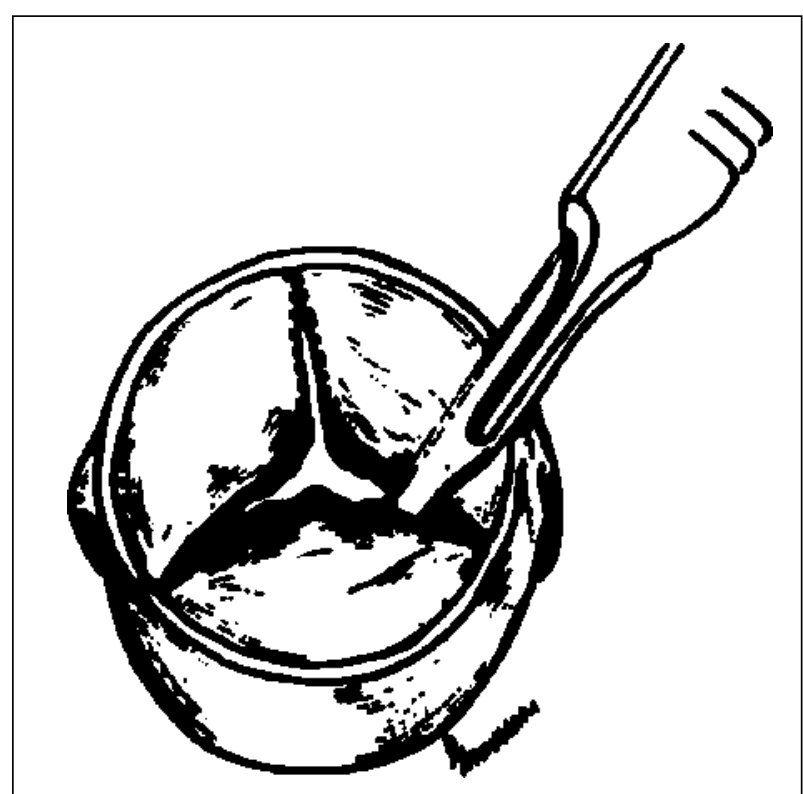

Fig. 1 - Debridement of cusps and aortic valve commissurotomy.

biological membranes. Conservative operations should aim at elimination of valve reflux with long lasting results without incurring any important left ventricle-aorta pressure gradients. The available techniques include:

Resuspension of cusp free edge - This method, proposed by Garamella ${ }^{13}$ and Trusler ${ }^{15}$, consists of plication of the redundant cusp free edge adjacent to one of the commissures with a transfixing U pledgeted polipropilene stitch fastened to the contiguous aortic ring (fig. 3). This plication should be done carefully to avoid lacerating the cusp. Eventually, in case the correction proves unsatisfactory, an aortic wall plication (aortoplasty) at the level of the commissures can be added ${ }^{44}$.

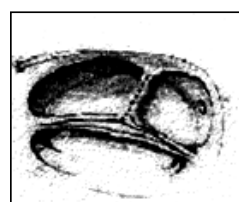

A

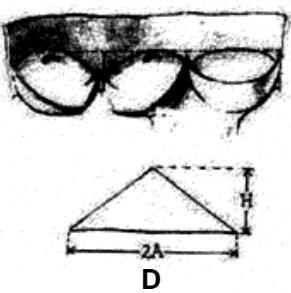

Fig. 2 - Resection of the rudimentary raphe and tricuspidization, with the aid of biological tissue preserved in glutaraldehyde, for the correction of the congenital stenosis of bicuspid aortic valve.
Reconstructive surgery for aortic valve disease

Commissuroplasty - This technique consists of plication of the aortic wall at the commissural level with $\mathrm{U}$ stitches anchored on nonabsorbable material (we favor bovine pericardium). This technical artifice, described by Cabrol ${ }^{14}$ and popularized by Cosgrove ${ }^{3}$, reduces the sinotubular ring diameter and increases the commissural length generating a wider cusp coaptation surface during aortic valve closure (fig. 4). This procedure is almost obligatory in aortic valve regurgitation due to sinotubular ring dilation.

Additional subcommissural stitches may sometimes be necessary to provide for additional increases in cusp coaptation, although it is desirable to gauge the valve annulus with Hegar candles before and after having completed the procedure, keeping in mind that in the average weight adult, for example, the valve should be adjusted down to not less than a $19 \mathrm{~mm}$ candle.

Plication of the aortic ring - This reduction annuloplasty is performed with a continuous mattress suture running along the base of the cusps ${ }^{1}$, but its clinical application has been quite controversial.

Triangular resection - This procedure can be applied to one or more redundant or prolapsed cusps. After recognizing the area of redundant cusp tissue, it is excised by trian-

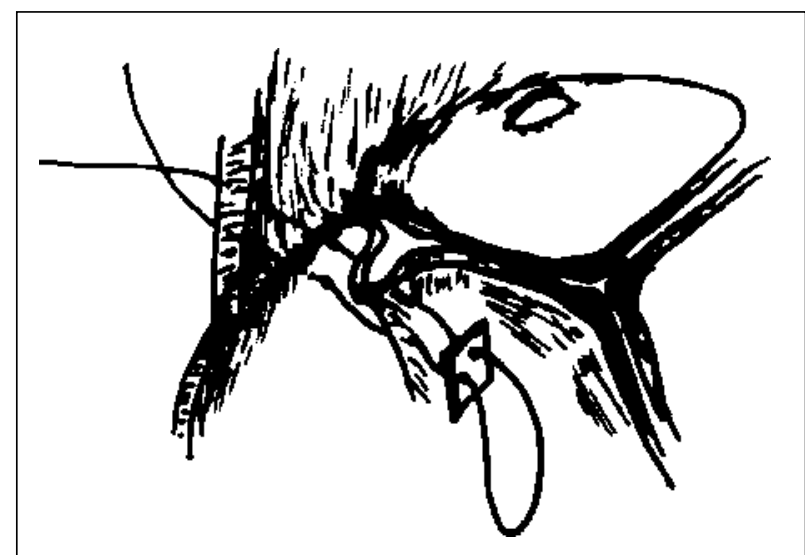

Fig. 3 - Resuspension of the redundant free edge of aortic cusp.

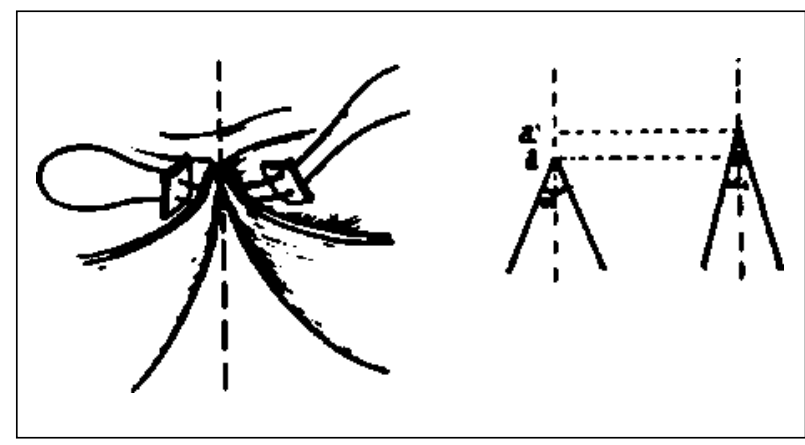

Fig. 4 - Commissuroplasty: Jointing stitches of the aortic cusps implantation bases ticas; and 1: commissure angles before and after the commissuroplasty; a and a': commissural plane before and after the plasty. 
gular resection and the cusp free edges are sewn together with a continuous double polypropilene suture (fig. 5). As a result, the cusp resumes its normal shape, allowing for the return of harmonic cusp coaptation and valve competence. This procedure is applicable to tri- and bicuspid aortic valves. In the bicuspid valves, it is common to find the redundancy of the cusp tissue close to the false commissure, altogether with local fibrotic thickening associated or not with calcific deposits. This technique is most useful for valvoplasty for regurgitation due to cusp prolapse.

Aortic wall plication - The diameter of the sinotubular ring is adjusted down to a fixed and appropriate size that is generally quite similar to the normal diastolic sinotubular ring measurement. By considering that the cusp free border length corresponds to the diameter of the sinotubular ring, it is quite easy to calculate the circumference of that ring. A strip as long as the expected sinotubular ring perimeter is fashioned from dacron felt or other similar material and attached to the outside of the aorta at the commissural plane with pledgeted mattress polypropilene stitches passed from the inside out, and equally distributed between the commissures ${ }^{43}$. This technique of aortic plication may be accomplished by fixing the dacron felt strip internally as well.

Aortic valvoplasty - This is a rather complex procedure, proposed by David ${ }^{4}$, applied to the surgical correction of aortic regurgitation due to annuloaortic dilation in the presence of an otherwise normal aortic valve with preserved cusp anatomy. It consists of ascending aorta and sinuses of Valsalva replacement with a tubular prosthesis whose proximal extremity is sutured to the aortic root thus recreating the sinuses of Valsalva and resuspending the aortic valve cusps. The coronary ostia are reimplanted into the tubular prosthesis.

Patching of perforated cusps - Loss of substance of the cusps, usually, caused by infectious endocarditis can lead to serious aortic valve incompetence and be associated with fistulization of the sinuses of Valsalva to the adjacent heart chambers. Correction of these lesions can be made by suture patching a piece of fresh or glutaraldehyde treated

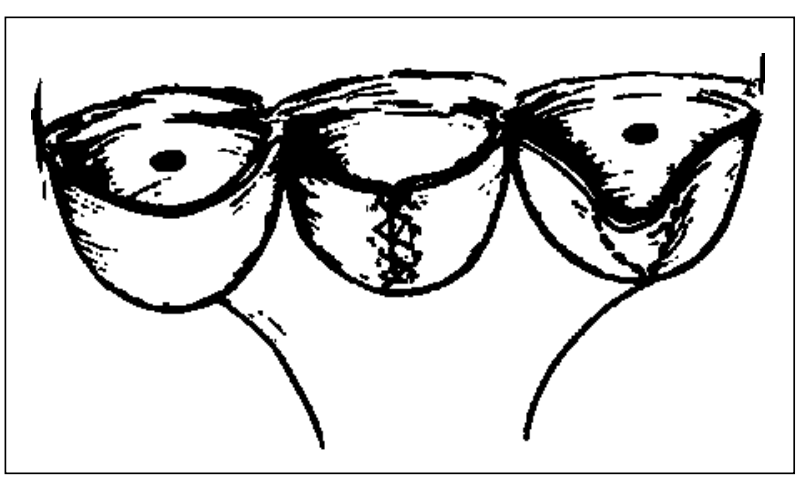

Fig. 5 - Triangular resection of prolapsed cusp with double continuous sutures. autologous pericardium, as well as glutaraldehyde tanned bovine pericardium ${ }^{45}$.

C) Combined, stenotic and insufficient aortic valve As the presence of fibrotic cusp retraction is commonplace in these lesions, particularly when due to rheumatic etiology, the plastic correction is usually burdened by the progression of the rheumatic disease. For combined lesions, besides liberation of the commissural fusions and removal of fibrotic and calcified areas, valve competence can be restored by using bovine pericardium to patch the gap resulting from detaching the cusp from its implantation base in between the commissures ${ }^{31,32}$. An alternative technique, proposed by Al Fagih, et al ${ }^{30}$ and Duran ${ }^{2}$, enlarges the cusps with a bovine pericardium patch sutured to the leaflet free margin. Cusp enlargement obtained with both techniques provides for adequate cusp coaptation and consequent valve competence.

\section{Experience of the authors}

The experience of the authors with aortic valvoplasty for acquired aortic valve disease includes 48 (4\%) cases from a total number of 1150 valve operations. Median age of the patients at operation was $28.8 \pm 14.4$ years, with $25(52 \%)$ female patients. In $16(33 \%)$ patients, the operation involved only the aortic valvoplasty. In $17(33 \%)$, associated procedures in another valve, mainly the mitral, were performed. Isolated aortic valve commissurotomy was done in $6(13 \%)$ patients, and this same procedure was employed in association with a mitral valve operation in 9 $(19 \%)$ other patients. From August, 1988 to June, 1995, 14 patients were operated upon by the cusp extension technique developed by the authors.

On the basis of previous experience with posterior leaflet advancement with homologous dura mater or glutaraldehyde tanned bovine pericardium ${ }^{29}$ for surgical treatment of mitral insufficiency, a similar technique was devised by us for correction of aortic valve regurgitation. The initial idea involved enlarging one or more of the cusps, in association or not with commissural resuspension. Bovine pericardium was selected for commissure to commissure cusp enlargement after previously detaching the retracted cusp from its base of implantation ${ }^{31,32}$.

After opening the ascending aorta and cardioplegia administration directly into the coronary ostia, rigorous evaluation of the valve is carried out. A temporary fine suture is then applied to temporarily bring together the noduli of Arantius and a partial detachment of the most retracted cusp is carried out, taking care to extend the cusp incision to very close to the commissures. This incision can even reach the valvar ring so that good fixation tissue at this point is provided for suturing to the bovine pericardium patch at the commissural level. Polypropilene suture then completes the patching. The bovine pericardium patch must be tailored to an oval shape with its major axis equal to the cusp base (figs. 6 and 7). This technique was used in 12 
patients. A technical modification was introduced in the last two cases, where cusp base extension was associated with cusp free edge triangular extension with the same material (fig. 8). Two cusps were enlarged in one case and only one cusp in the other. Follow-up is complete.

One patient died from bacterial endocarditis 7 months p.o. Another patient was reoperated upon 33 months p.o. due to progression of rheumatic disease and had a StarrEdwards prosthesis implanted in the aortic position.

Mild aortic valve regurgitation, a universal finding in early p.o., has gradually worsened over the first years (fig. 9) although, curiously, the patients continue clinically well.

Some considerations on the acquired experience with this technique can so far be summarized: 1) the technique is reproducible, with good immediate results; 2 ) one or more cusps can be enlarged, and one should select the most damaged one(s) to deal with; 3) by adding other reconstructive procedures in association with this technique, the results should improve; 4) good valve reconstruction and clinical improvement resulted from the technical variant employed in the last two cases; 5) bacterial endocarditis as well as

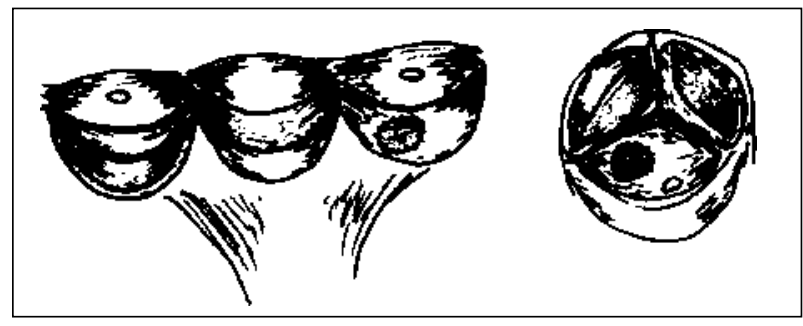

Fig. 6 - Restorations of the cusps with bovine pericardium starting from the base implantation and of the free edge of the peaks; patch of bovine pericardium in the center of the aortic cusp (from the left to the right).

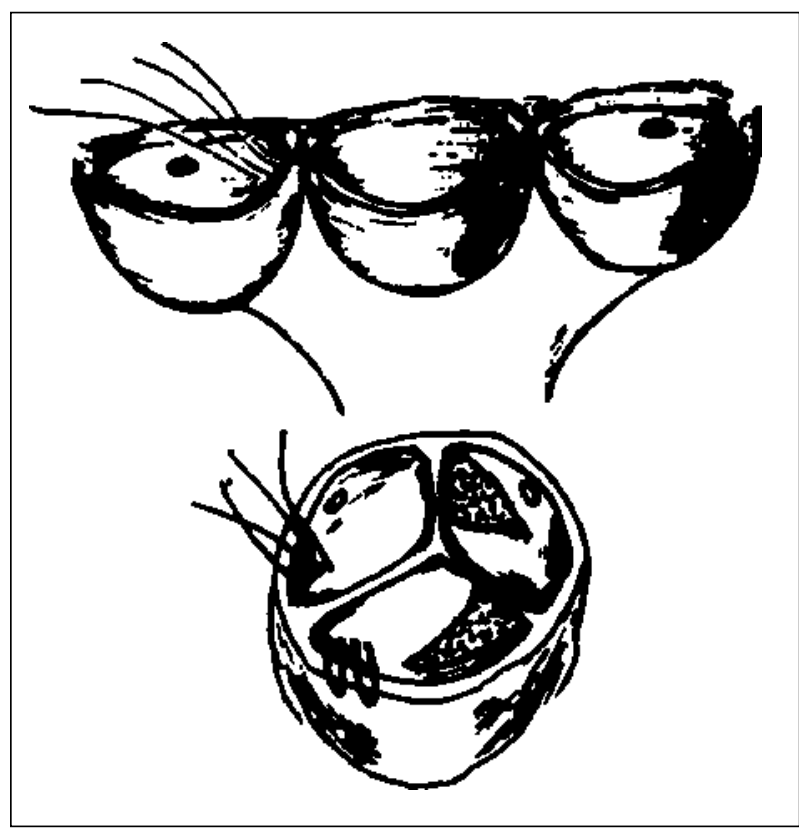

Fig. 7 - Amplification of the posterior cusp with bovine pericardium starting from its implantation base.

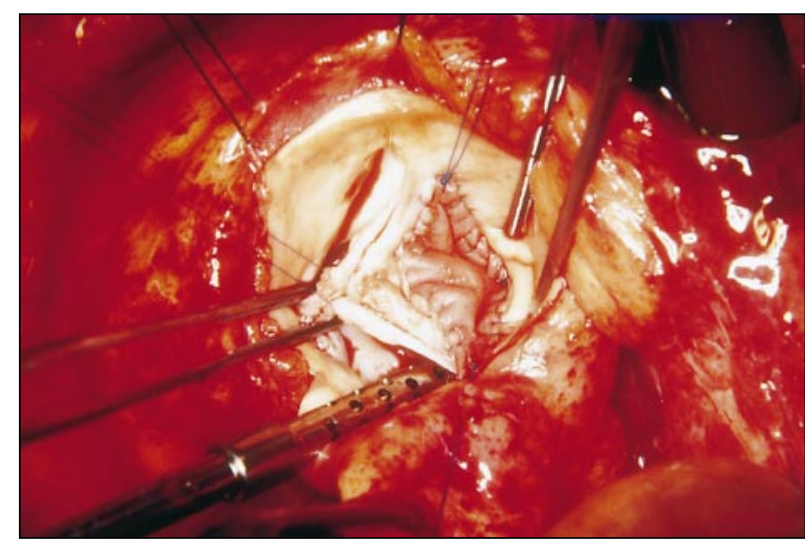

Fig. 8 - Intraoperative aspect of the aortic cusp amplification with bovine pericardium including the base implantation of the cusp free edge.

progression of the rheumatic process are a constant concern; 6) the long-term behavior of the native cusp tissue regarding its further fibrotic degeneration is also worrisome; 7) as it is the case for the mitral valve, it seems that the bovine pericardium patch outlives the native cusp; 8) long-term clinical evolution must be awaited for a more definitive appreciation of the results although, so far, clinical results seem similar to the ones afforded by aortic valve bioprosthetic replacements.

\section{State of the art}

Conservative surgical procedures for the treatment of aortic valve lesions (commissurotomy, fibrotic debulking and decalcifications) are performed by most services. Shapira ${ }^{5}$, after a 7-year follow-up study, reported an $87 \%$ symptom free population and recurrence of valve dysfunction mostly in rheumatic and congenital valve disease patients.

From a technical challenge point of view conservative treatment of the insufficient aortic valve has been surrounded by great attention and controversy. This results particularly from the fact that the myocardium seems to tolerate the valvar lesion well but, on the other hand, surgical treatment almost always requires prosthetic valve replacement.

Plastic correction of regurgitant aortic valve lesions remains, so far, scarcely employed, whether because of not being widely accepted, whether because it receives less attention or due to the technical difficulties caused by the anatomical characteristics of the aortic valve. The permanence of the classic notion that treatment for an incompetent aortic valve automatically implies its substitution by a prosthesis has been reinforcing the general trend towards delaying surgical repair of the native valve. Thus, the patients end up being operated on while in worse clinical condition, sometimes, already beyond consideration for trying a conservative operation.

In the past, several isolated surgical techniques have been advocated. However, the best results for aortic valve 


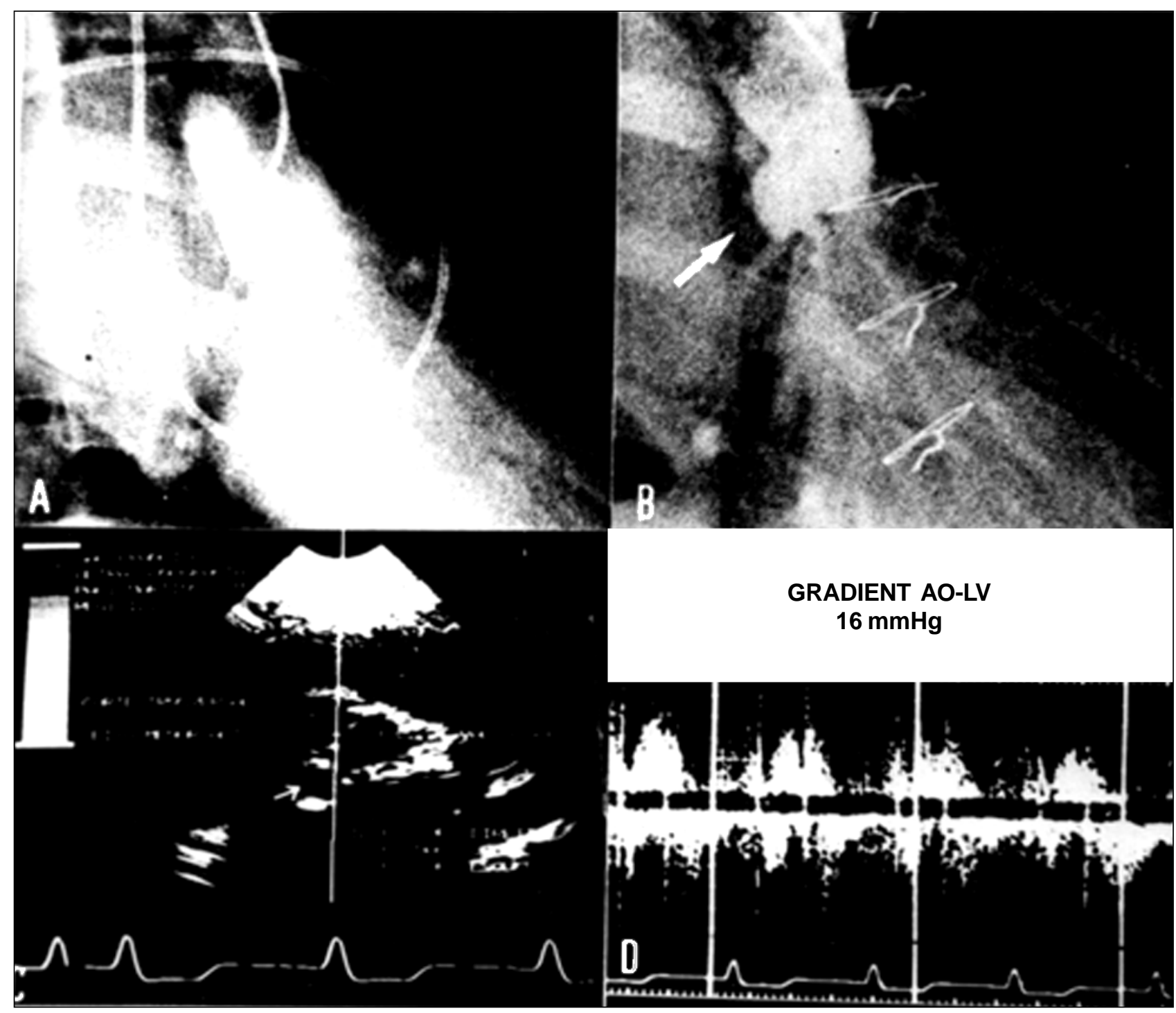

Fig. 9-A and B: Aortography in diastole before and after the restoration of the posterior aortic cusp with bovine pericardium; C and D: postoperative echodopplercardiography.

preservation are usually obtained by the conjugation of varied surgical steps, although isolated procedures can eventually solve valvar dysfunction.

Cabrol, commenting on a paper by Cosgrove ${ }^{3}$, reported excellent results with aortic commissuroplasty in 12 patients followed-up for 25 years. The interest in this particular technique of aortic valvoplasty has been increasing since 1971, when Carpentier ${ }^{1}$ started out correcting aortic incompetence by associating triangular resection with a restricting circular suture at the base of implantation of the cusps. His results, after 12 years of follow-up, were very good, with a $3.3 \%$ mortality rate, $13 \%$ reoperations and moderate residual regurgitation in $15 \%$ of the cases. In 1974, Duran ${ }^{46}$ started to use Cabrol, et al annuloplasty ${ }^{14}$, associated with annuloplasty of the sinutubular ring and other procedures with very good results, although his $6 \%$ mortality rate was almost twice that reported by Carpentier.

In 1986, Frater ${ }^{47}$ described his limited experience related to the circular suturing of the sinotubular ring reinforced with an external band. Having started in 1988, Cosgrove, et $\mathrm{al}^{38}$ reported a similar, but larger, experience associating Cabrol annuloplasty ${ }^{14}$ with triangular resection, with good results at short-term follow-up. This same group presented in 199472 cases of bicuspid aortic valvoplasty ${ }^{39}$; this time with a larger follow-up. They used and modified the techniques introduced by Cabrol, et al ${ }^{14}$ and Carpentier ${ }^{1}$, with very good clinical results. No mortality resulted, $94 \%$ of the patients were in functional class I (N.Y.H.A.), $6 \%$ in class II and only 6 patients were referred for reoperation.

If we consider Cabrol's good results ${ }^{3}$, over a 27 year follow-up, as well as Carpentier's $\mathrm{s}^{1}$, over a 12-year period, one can accept a good perspective for aortic valve preservation techniques even though these series treated mostly congenital lesions. Of course, for aortic valve disease of rheumatic origin, the results should be worse due to progression of the disease.

Cases of pure aortic valvar incompetence as well as cases of mixed lesions of the aortic valve, most of rheumatic 
etiology, whether treated by the aortic repair techniques proposed by Al Fagih et al ${ }^{30}$, Duran ${ }^{2}$ or ourselves ${ }^{31,32}$ seem to show some exciting results. In Duran's 54 patients operated on over a 44-month period who received tanned pericardium cusp extensions, no deaths occurred. In our previously mentioned experience 1 late death occurred due to bacterial endocarditis and only one reoperation at 33 months p.o. was required. In the latter case, in which heterologous bovine pericardium was used for both mitral and aortic valvoplasty, we were impressed at finding that fibrotic degeneration of the native aortic valve cusps was severe, and the mitral valve looked much better preserved regarding both the native valve structures and the bovine pericardium patch.

Limitations to conservative aortic valve surgery due to the presence of cusp calcifications motivated the application of ultrasonic devices to perform valve decalcification that if successful might lead the way to the preservation of the aortic valve in senior patients. Although use of ultrasound aortic valve decalcification had a period of great enthusiasm, with exciting short- and medium-term results ${ }^{41}$, over the long run several problems reappeared, mainly linked to regurgitation and fibrosis, which resulted in abandonment of the technique ${ }^{38}$.

Pre- and intraoperative evaluation are essential for proper selection of the techniques to be applied in each particular case. The surgeon should aim at readjusting the positioning and shape of the cusps so that a perfect valvular coaptation is regained during ventricular diastole, thus correcting the regurgitant lesion. After completing surgical correction, transesophageal echocardiography is of utmost importance in evaluating the immediate functional result, at the end of cardiopulmonary bypass and after normal heart function is re-established. Another way to evaluate aortic competence is to check for aortic valve reflux while looking through the mitral valve, in cases treated for lesions in both valves, while the aorta is temporarily declamped. A reflux to the left ventricle about 10 to $15 \%$ of the systemic flow supplied by the heart- lung machine is acceptable. An abrupt decrease in the arterial pressure of more than $30 \mathrm{mmHg}$ during this procedure is indicative of important valvar regurgitation that needs further correction. Whenever valvoplasty turns out unsatisfactorily, one should not hesitate to return to cardiopulmonary bypass in order to try additional correction or to replace the valve. This attitude is very important for small functional imperfections may, in a short period of time, aggravate to the point of imposing reoperation.

The ever-present criticism towards anticoagulation together with the inherent complications of valvar prostheses make valvar preservation a very attractive alternative. We believe, based on data currently available, that conservative aortic valve surgery is an effective and potentially durable operation that deserves larger diffusion for the benefit of many patients. On the other hand, this recommendation is also valuable in stimulating a salutary competition between plastic restoration and the development or improvement, or both of new synthetic valve prostheses.

Another important topic to be considered has to do with the type of biological material that should be used for reparative aortic valve operations. A recent paper by Duran ${ }^{48}$ tried to answer this point by addressing the clinical behavior of glutaraldehyde preserved bovine and autologous pericardium patches, and after an 8-year follow-up period, more favorable results were attained with autologous pericardium ${ }^{45}$. The use of this latter biological membrane, more subtle methods for sizing the patch materials to be used for cusp repair as well as suture material selection remain under investigation ${ }^{49}$.

Scientific progress shall ultimately boost the current acceptance level for conservative aortic valve surgery. Growing confidence in the efficacy of the operation will allow a more expeditious indication for surgical treatment, as is already now the case in mitral valve repair. This change of attitude will certainly make it possible for patients to be sent for operation in better ventricular function and lesser degrees of structural valvar degeneration.

Currently available scientific data allow us to consider aortic valvoplasty as a concrete reality that one should try to pursue. Two Brazilian experiences deserve mention in this challenging field. One comes from InCor, where 31 patients were operated on from August, 1980 to May, 1995, with different techniques already described in this review, and followed-up for about 70 months ${ }^{50}$. The other report is from Aracaju, where Mendonça et al accumulated 105 adult patients who have completed a 30.2 month follow-up. The authors additionally adopted a philosophical determination to extend aortic valve conservation in children, which represented most of their experience (64.8\%), with a mean follow-up time of 21.7 months (Teles de Mendonça - personal communication, 1999).

Acknowledgements: To Dr. Rui Yamasaki who took the responsability of the illustrations

\section{References}

1. Carpentier A. Cardiac valve surgery - the "French correction". J Thorac Surg 1983; 86: 323-37.

2. Duran CG. Present status of reconstructive surgery for aortic valve disease. J Card Surg 1993; 8: 443-52.

3. Cosgrove DM, Rosenkranz ER, Hendren WG, bartlett JC, Stewart WJ. Valvuloplasty for aortic insufficiency. J Thorac Cardiovasc Surg 1991; 102: 571-7.

4. David TE. Aortic valve repair in patients with Marfan syndrome and ascending aorta aneurysms due to degenerative disease. J Card Surg 1994; 9(suppl): 182-7.
5. Shapira N, Lemole GM, Fernandez J, et al. Aortic valve repair for aortic stenosis in adults. Ann Thorac Surg 1990; 50: 110-20.

6. Tuffler T. Etat actuel de la chirugie intrathoracique. XVII Internat Congress Med, London, 1913; Sec VII(Pt II): 247-9.

7. Bailey CP, Bolton HE, Jamison WL, et al. Comissurotomy for rheumatic stenosis. I. Surgery. Circulation 1954; 9: 22-31.

8. Swan WK, Bradsher JT Jr, Rodriguez Arroyo J. Intracardiac surgery with the aid of artificial operative tunnels. J Thorac Surg 1954; 28: 266-72. 
9. Brock RC. Surgical treatment of aortic stenosis. Br Med J 1957; 1: 1019-28.

10. Muller WH, Kattus AA, Dammann JF, et al. Experiences in the surgical treatment of aortic stenosis. J Thorac Surg 1954; 28: 516-35.

11. Lillehei CW, Gott VL, De Wall RA, et al. The surgical treatment of stenotic or regurgitant lesions of the mitral and aortic valves by direct vision utilizing a pump oxygenator. J Thorac Cardiovasc Surg 1958; 35: 154-91.

12. Mulder DG, Kattus AA, Longmire WP. The treatment of acquired aortic stenosis by valvuloplasty. J Thorac Cardiovasc Surg 1960; 40: 731-43.

13. Garamella JJ, Cruz AB Jr., Heupel WH, et al. Ventricular septal defect with aortic insufficiency: Successful surgical correction of both defects by the transaortic approach. Am J Cardiol 1960; 5: 266-72.

14. Cabrol C, Guiraudon G, Bertrand M, et al. Le traitment de l'insuffisance aortique par l'annuloplastie aortique. Arch Mal Coeur 1966; 59: 1305-12.

15. Trusler GA. Moes CAF, Kidd BSL. Repair of ventricular septal defect with aortic insufficciency. J Thorac Cardiovasc Surg 1973; 66: 394-403.

16. Harken DH, Soroff HS, Taylor WJ, et al. Partial and complete prostheses for aortic insufficiency. J Thorac Cardiovasc Surg 1960; 40: 744-62

17. Ross DN. Surgical reconstruction of the aortic valve. Lancet 1963; ii: 571-4.

18. Bjork VO, Hultquist G. Teflon and pericardial aortic valve prostheses. 1964; 47 : 693-701.

19. Edwards WS. Aortic valve replacement with autogenous tissue. Ann Thorac Surg 1969; 8: 126-31

20. Bahnson HT, Hardesty RL, Baker LD Jr, et al. Fabrication and evaluation of tissue leaflets for aortic and mitral valve replacement. Ann Surg 1970; 171 939-47.

21. Senning A. Aortic valve replacement with fascia lata. Acta Chir Scand 1966; (suppl): 17-20.

22. Senning A. Fascia lata replacement of aortic valves. J Thorac Cardiovasc Surg 1967; 54: 465-70

23. Senning A, Rothlin M. Reconstruction of the aortic valve with fascia lata, initial and long-term results. Vasc Surg 1973; 7: 29-35.

24. Senning A, Rothlin M. The late fate of autologous fascia lata valve grafts in the aortic position. Israel J Med Sci 1975; 11: 179-84

25. Puig LB, Verginelli G, Bellotti G, et al. Homologous dura mater cardiac valve. Preliminary study of 30 cases. J Thorac Cardiovasc Surg 1972; 64: 154-60.

26. Batista RJV, Dobrianskij A, Comazzi M Jr, et al. Clinical experience with stentless pericardial aortic monopatch for aortic valve replacement. J Thorac cardiovasc Surg 1990; 93: 19-26.

27. Yacoub M, Khaghani A, Dhalla N, et al. Aortic valve replacement using unstented dura or calf pericardium: early and long-term results. In: BodnarE, Yacoub M, (eds). Biologic and Bioprosthetic Valves. New York: Yorke Medical Books, 1986; 684-90.

28. Khaghani A, Mankand P, Dhalla N, et al. Aortic valve replacement using unstented dura or calf pericardium; Early and medium term results. J Am Coll Cardiol 1987: 9: 8A.

29. Evora PRB, Ribeiro PJF, Brasil JCF, et al. Experiência com dois tipos de técnicas para tratamento cirúrgico da insuficiência mitral. I. Prótese com preservação de elementos do sistema valvar; II. Plastia valvar com reconstrução e avanço do folheto posterior. Rev Bras Cir Cardiovasc 1990; 5: 86-98.
30. Al Fagih MR, Al Kassab SM, Ashmeg A. Aortic valve repair using bovine pericardium for cusp extension. J Thorac Cardiovasc Surg 1988; 96: 760-4.

31. Bongiovani HL, Ribeiro PJF, Evora PRB, et al. Plastia valvar aórtica por ampliação de válvula com pericárdio bovino: nota prévia. Rev Bras Cir Cardiovasc 1988; 3: 130-3.

32. Ribeiro PJF, Bongiovani HL, Evora PRB, et al. Plastia valvar aórtica por ampliação de válvula(s) com pericárdio bovino. Rev Bras Cir Cardiovasc 1990; 5: 99-105.

33. Thubrikar M. Geometry of the aortic valve. In: Thubrikar M, (ed). The Aortic Valve. Boca Raton, Fl: CRC Press, 1990: 1-20.

34. Sutton III JP, HO SY, Anderson RH. The forgotten interleaflet triangles: A review of the surgical anatomy of the aortic valve. Ann Thorac Surg 1995; 95: 419-27.

35. Robicsek F. Leonardo da Vinci and the sinuses of Valsalva. Ann Thorac Surg 1991; 52: 328-35.

36. Brown AH, Davies PGH. Ultrasonic decalcification on calcified cardiac valves and annuli. Br Med J 1972; 3: 274-7.

37. Freeman WE, Schaff HV, King RM, Orszulak TA. Ultrasonic aortic valve decalcification: Doppler echocardiographic evaluation (Abstract). J Am Coll Cardiol 1988; 11: 229A.

38. Cosgrove DM, Ratliff NB, Schaff HV, Edwards WD. Aortic valve decalcification: history repeated with a new result. Ann Thorac Surg 1990; 49: 689-90.

39. Fraser CD Jr, Wang N, Mee RBB, et al. Repair of insufficient bicuspid valves. Ann Thorac Surg 1994; 58: 386-90.

40. Otaki M. A new modification of debridement valvuloplasty for acquired aortic valve disease. J Card Surg 1994; 9: 103-8.

41. Kellner HJ, Pracki P, Hildebrandt A, Binner C, Eisele G, Struck E. Aortic valve debridement by ultrasonic surgical aspirator in degenerative, aortic valve stenosis: follow-up with Doppler echocardiography. J Cardiothorac Surg 1996: 10: 498-504

42. Tolan JT, Daubeney PE, SlavikZ, Keeton BR, Salmon AP, Monro JL. Aortic valve repair of congenital stenosis with bovine pericardium. Ann Thorac Surg 1997; 63: 465-9.

43. Kadri MA, Hovaguimian H, Starr A. Commissurotomy and bileaflet pericardial augmentation-resuspension for bicuspid aortic valve stenosis. Ann Thorac Surg 1997; 63: 548-50

44. Hisatomi $\mathrm{K}$, Isomura $\mathrm{T}$, Sato $\mathrm{T}$, et al. Aortoplasty for aortic regurgitation with ventricular septal defect. J Thorac Cardiovasc Surg 1994; 108: 396-7.

45. Mendonça JT, Wanderley Neto J, Carvalho M, et al. Cirurgia valvarna infância: um novo aspecto de ação. Rev Bras Cir Cardiovasc 1992; 7: 174-9.

46. Duran CG. Reconstructive technique for aortic rheumatic disease. J Card Surg 1988; 3: 238

47. Frater RWM. Aortic valve insufficiency due to aortic dilatation: correction by sinus rim adjustement. Circulation 1986; 74(suppl 1): 136-42.

48. Duran CM, Gometza B, Shahid M, Al-Halees Z. Treated bovine and autologous pericardium for aortic valve reconstruction. Ann Thorac Surg 1998; 66(6 suppl): S166-9.

49. Love JW. Autologous pericardial reconstruction of semilunar valves. J Heart Valve Dis 1998, 7: 40-7.

50. Neves Jr MT, Pomerantzeff PM, Brandão CMA, et al. Plástica da valva aórtica em pacientes portadores de insuficiência aórtica: resultados imediatos e tardios. Rev Bras Cir Cardiovasc 1996; 11: 151-60. 